\title{
The CSIRO Mk3L climate system model v1.0 coupled to the CABLE land surface scheme v1.4b: evaluation of the control climatology
}

\author{
J. Mao ${ }^{1,2,3}$, S. J. Phipps ${ }^{2,4}$, A. J. Pitman ${ }^{2,4}$, Y. P. Wang ${ }^{1}$, G. Abramowitz ${ }^{2,4}$, and B. Pak ${ }^{1}$ \\ ${ }^{1}$ Centre for Australian Weather and Climate Research: A partnership between CSIRO and the Bureau of Meteorology, \\ Aspendale, Victoria, Australia \\ ${ }^{2}$ Climate Change Research Centre, University of New South Wales, Australia \\ ${ }^{3}$ Environmental Sciences Division, Oak Ridge National Laboratory, Oak Ridge, Tennessee, USA \\ ${ }^{4}$ ARC Centre of Excellence for Climate System Science, University of New South Wales, Australia
}

Received: 24 June 2011 - Published in Geosci. Model Dev. Discuss.: 20 July 2011

Revised: 28 November 2011 - Accepted: 28 November 2011 - Published: 8 December 2011

\begin{abstract}
The CSIRO Mk3L climate system model, a reduced-resolution coupled general circulation model, has previously been described in this journal. The model is configured for millennium scale or multiple century scale simulations. This paper reports the impact of replacing the relatively simple land surface scheme that is the default parameterisation in Mk3L with a sophisticated land surface model that simulates the terrestrial energy, water and carbon balance in a physically and biologically consistent way. An evaluation of the new model's near-surface climatology highlights strengths and weaknesses, but overall the atmospheric variables, including the near-surface air temperature and precipitation, are simulated well. The impact of the more sophisticated land surface model on existing variables is relatively small, but generally positive. More significantly, the new land surface scheme allows an examination of surface carbon-related quantities including net primary productivity which adds significantly to the capacity of Mk3L. Overall, results demonstrate that this reduced-resolution climate model is a good foundation for exploring long time scale phenomena. The addition of the more sophisticated land surface model enables an exploration of important Earth System questions including land cover change and abrupt changes in terrestrial carbon storage.
\end{abstract}

Correspondence to: S. J. Phipps

(s.phipps@unsw.edu.au)

\section{Introduction}

There is a need for a hierarchy of climate models ranging from the fully-coupled climate system models integrated at the highest spatial resolution possible, through to heavily parameterised models that resolve spatial resolution in one dimension (McAvaney et al., 2001). Global climate models, that resolve the spatial dimension explicitly, can conveniently be classified into "complex" models and Earth System Models of Intermediate Complexity (EMICs). In reality, the borders between these two types of models are blurred. Claussen et al. (2002) provides guidance on differentiating between types of models. McAvaney et al. (2001) and Randall et al. (2007) discuss evaluation and use of these models in terms of their role in the assessment reports of the Intergovernmental Panel on Climate Change (IPCC).

This paper describes and evaluates an upgraded version of the Commonwealth Scientific and Industrial Research Organisation (CSIRO) Mark 3 reduced-resolution model (Mk3L; Phipps et al., 2011). This model is not a "state-ofthe-art" climate system model because several parameterisations, and the model resolution, are chosen for computational efficiency. The model is also not a classic EMIC in that the atmospheric and ocean dynamics, grid-structures and most parameterisations are resolved in comparable ways to advanced climate system models. Mk3L is best described as a reduced-resolution climate model; its parameterisation and resolution would have been state-of-the-art for the Second Assessment Report of the IPCC (Houghton et al., 1996) in that the model contains some sophisticated physics (in particular terrestrial processes), as well as relatively complex representations of sea ice, ocean and atmospheric processes.

Published by Copernicus Publications on behalf of the European Geosciences Union. 
The CSIRO Mk3L climate system model represents a system configured for specific applications: long-time scale or very-large ensemble simulations. The model can be integrated for millennium-length simulations, or used to conduct hundreds of individual realisations to explore the probability of specific events such as terrestrial carbon collapse (Cox et al., 2000), probability of drought or reliability of monsoon systems. In this paper we focus on the impact of coupling a new land surface model with the capacity to simulate terrestrial carbon fluxes. Adding this capacity is a key step in moving from a climate system model to an Earth System Model. This paper explicitly builds on Phipps et al. (2011), which describes version 1.0 of Mk3L. Here we focus on how the near-surface climatology of the model is affected by including a more sophisticated land surface model and demonstrate the model's skill in capturing some new variables unavailable in the default version of the model.

\section{Model description}

Mk3L is fully documented in Phipps et al. (2011) and this description is not repeated here. The model has a reduced spatial resolution, with the atmospheric component having a horizontal resolution of $5.625^{\circ}$ by $\sim 3.18^{\circ}$ and 18 vertical levels. Details are provided here on the two land surface models used: a relatively simple "second generation" scheme and a more advanced "third generation" model (see Sellers et al., 1997).

\subsection{K91 land surface model}

The simple land surface model is an enhanced version of the soil-canopy scheme of Kowalczyk et al. $(1991,1994)$ and is hereafter referred to as K91. The model includes nine soil and 13 vegetation types, as well as a multi-level soil and snow cover scheme. Seasonally-varying values are provided for the albedo and roughness length and annual-mean values are provided for the vegetation cover fraction. The stomatal resistance is calculated as a function of air temperature, vapour pressure deficit, incident radiation flux density at canopy height and canopy leaf area index (see Jarvis, 1976). The soil model has six vertical layers, each of which has a pre-set thickness. Soil temperature and the liquid water and ice contents are calculated as prognostic variables. Runoff occurs once the surface layer becomes saturated, and is assumed to travel instantaneously to the ocean. The snow model computes the snow albedo and the temperature, density and thickness of three snowpack layers. The maximum snow depth is set at $4 \mathrm{~m}$ (equivalent to $0.4 \mathrm{~m}$ of water). $\mathrm{K} 91$ is embedded within Mk3L and is not configured to run offline.

The K91 model has been extensively tested and evaluated and was demonstrated to perform well in a series of intercomparison studies (e.g. Henderson-Sellers et al., 1995). However, the capacity to simulate the feedback from climate change and variability resulting from changes in the terrestrial carbon balance has become increasingly important. The K91 model lacks this capacity and this has led to the development of a new representation of terrestrial processes that is now coupled to $\mathrm{Mk} 3 \mathrm{~L}$.

\subsection{The CABLE land surface scheme}

The Community Atmosphere Biosphere Land Exchange (CABLE) land surface scheme version 1.4b (Wang and Leuning, 1998; Kowalczyk et al., 2006; Abramowitz et al., 2008; Wang et al., 2011) is a "third-generation" land surface scheme. CABLE formally couples the fluxes of energy, water and carbon at the canopy scale as described by Wang and Leuning (1998).

CABLE consists of a number of sub-models representing canopy processes, soil, snow, carbon pool dynamics and soil respiration. CABLE has a considerable lineage. It builds on a land surface model, SCAM, developed by Raupach et al. (1997). SCAM was coupled to an atmosphere model and tested using field measurements (Finkele et al., 2003). SCAM includes the near field theory of turbulent transfer between soil, vegetation and atmosphere (see Raupach, 1989) and calculations of canopy aerodynamic properties as a function of canopy height and canopy leaf area index (see Raupach, 1994). SCAM was later improved by implementing a one-layer two-leaf canopy model formulated by Wang and Leuning (1998) based on a multilayer model of Leuning et al. (1995). The one layer model differentiates between sunlit and shaded leaves, hence two sets of physical and physiological parameters were devised to represent the bulk properties of sunlit and shaded leaves. Several improvements were made to the one layer model including allowance for non-spherical leaf distribution, an improved description of the exchange of solar and thermal radiation, and modification of the stomatal model of Leuning et al. (1995) to include the effects of soil water deficit on photosynthesis and respiration (Wang et al., 2001). Annual plant net primary productivity is determined from the annual carbon assimilation corrected for respiratory losses (see Wang and Barrett, 2003). The seasonal growth and decay of biomass is determined by partitioning of the assimilation product between leaves, roots and wood. The flow of carbon between the vegetation and soil is described at present by a simple carbon pool model (Dickinson et al., 1998). A multilayer soil model is used, with Richards' equation solved for soil moisture and the heat conduction equation solved for soil temperature. The snow scheme was also improved by including up to three layers of snow above the soil. The snow model computes the temperature, density and thickness of three snowpack layers, and the albedo of the snow surface as a function of the age of the top snow layer. Wang et al. (2011) provide full details of CABLE. 


\section{Off-line model evaluation}

Land surface schemes are commonly evaluated uncoupled from the host atmospheric model before coupled model experiments are performed. CABLE has been extensively evaluated using traditional and innovative measures of model performance (Abramowitz, 2005; Kowalczyk et al., 2006; Wang et al., 2007; Abramowitz et al., 2008; Wang et al., 2011). A full-scale evaluation of CABLE is not presented here (see Wang et al., 2011). However, in order to help interpret the results from the coupled simulations, an evaluation of the base-line surface climate of CABLE in terms of the model's capacity to simulate sensible and latent heat fluxes and a measure of carbon exchange is useful. We cannot, of course, evaluate CABLE's capacity in terms of precipitation, net radiation or air temperature in off-line simulations. These are prescribed based on observations in the case of air temperature and precipitation. They are also largely prescribed in the case of net radiation, because incoming solar and infrared radiation are provided from observations.

Figure 1 shows the simulation by CABLE of monthly averaged latent heat flux, sensible heat flux and net ecosystem exchange for the six locations detailed in Table 1. Sites were chosen based on the completeness and quality of their meteorological and flux measurements over whole year periods. This evaluation of a land surface scheme is not entirely legitimate as CABLE is designed to run in a global climate model reflecting large spatial scales and the observations are locally specific. CABLE also uses large-scale estimates of some key parameters, including monthly leaf area index, that may not be similar to the values of specific observational sites. This evaluation should therefore be considered more as a "benchmark" for the model against which further versions might be compared.

In the case of Fig. 1, CABLE replicates the observed latent heat flux, on a monthly timescale, at Norunda (forest), Tumbarumba (forest) and Tharandt (forest) reasonably well. The latent heat flux is shifted 1-2 months too early in simulations at Harvard Forest likely due to poor prescription of leaf area index at this site. This could probably be fixed if we used observed, site-specific data. While this would improve the simulation at this site, it would not improve confidence in the model coupled into Mk3L. There is a clear deficiency in CABLE's capacity to simulate Little Washita (grass) again likely related to mis-specification of leaf area index. For the sensible heat flux, CABLE captures the observations well at Tumbarumba and Metolius. A clear deficiency is apparent at Harvard Forest, Norunda and Tharandt, particularly in winter, but the summer and autumn simulations are good. Finally, in terms of net ecosystem exchange Tharandt is simulated very well and Metolius and Norunda reasonably. Harvard forest is simulated but with a 2-month lag. Clear deficiencies are obvious in Little Washita and Tumbarumba.

Another way to evaluate a land surface model is to explore how well it can capture the probability density function of the observed fluxes. This evaluates more than the mean, it explores the shape of an observed distribution, and the tails or more extreme values. Land surface schemes provide fluxes to and from the atmosphere on a time-step basis in a climate model and therefore need to capture the variability in fluxes as well as the mean. In addition, recent analyses of the impacts of land surface processes on extremes (Seneviratne et al., 2006; Fischer et al., 2007; Seneviratne et al., 2010) point to the need to evaluate land surface models in terms of their capacity to simulate more extreme conditions. Figure 2 shows the probability density function of latent heat, sensible heat and net ecosystem exchange derived using 30-min simulated and observed data. There is considerable skill in the model across the whole distribution that suggests CABLE is capturing a considerable amount of the variability around terrestrial processes. The limitations of the model apparent in Fig. 1 are also clear in Fig. 2 with CABLE simulating too frequent negative latent heat fluxes at Harvard Forest, Norunda and Tharandt. Washita and Tumbarumba are relatively skillfully captured with $87 \%$ and $88 \%$ of the observed probability density function matched. The skill is normally lower for the sensible heat flux and there are clear difficulties at Metolius, Norunda and Tharandt in the lower tails and midrange of the probability density function. The simulation of the more challenging NEE (which is a balance of a series of quite large fluxes) clearly highlights the distance CABLE still has to go to provide reliable estimates of this flux in a climate modelling system. There is some suggestion of skill at Tharandt and Harvard Forest but in all cases the probability density function is too centred on values around zero and fails to capture the observed upper range of the distribution. The lower range seems to be better captured.

Figures 1 and 2 highlight a suite of strengths and weaknesses in CABLE. For some places the model is very good, in others quite poor. This could be resolved via site-specific calibration of parameter values; if leaf area index was calibrated the simulations at many sites would improve considerably. However, this is not feasible within the coupled climate model and we provide Figs. 1 and 2 combined with Table 2 as an honest assessment of the model's skill in its global configuration. This cannot be compared to site-specific model evaluation studies that inevitably point to higher levels of skill because the model is calibrated or the model developer chooses site-relevent parameters. Indeed, in comparison with other land surface models, CABLE's performance is very competitive (see Abramowitz et al., 2008) although we do not underestimate the scale of the challenge in resolving the outstanding problems. The inclusion of this comparison against multiple sites is intended therefore as a benchmark of the skill in the current version of CABLE in capturing observed station data and to enable direct comparisons in the future. 

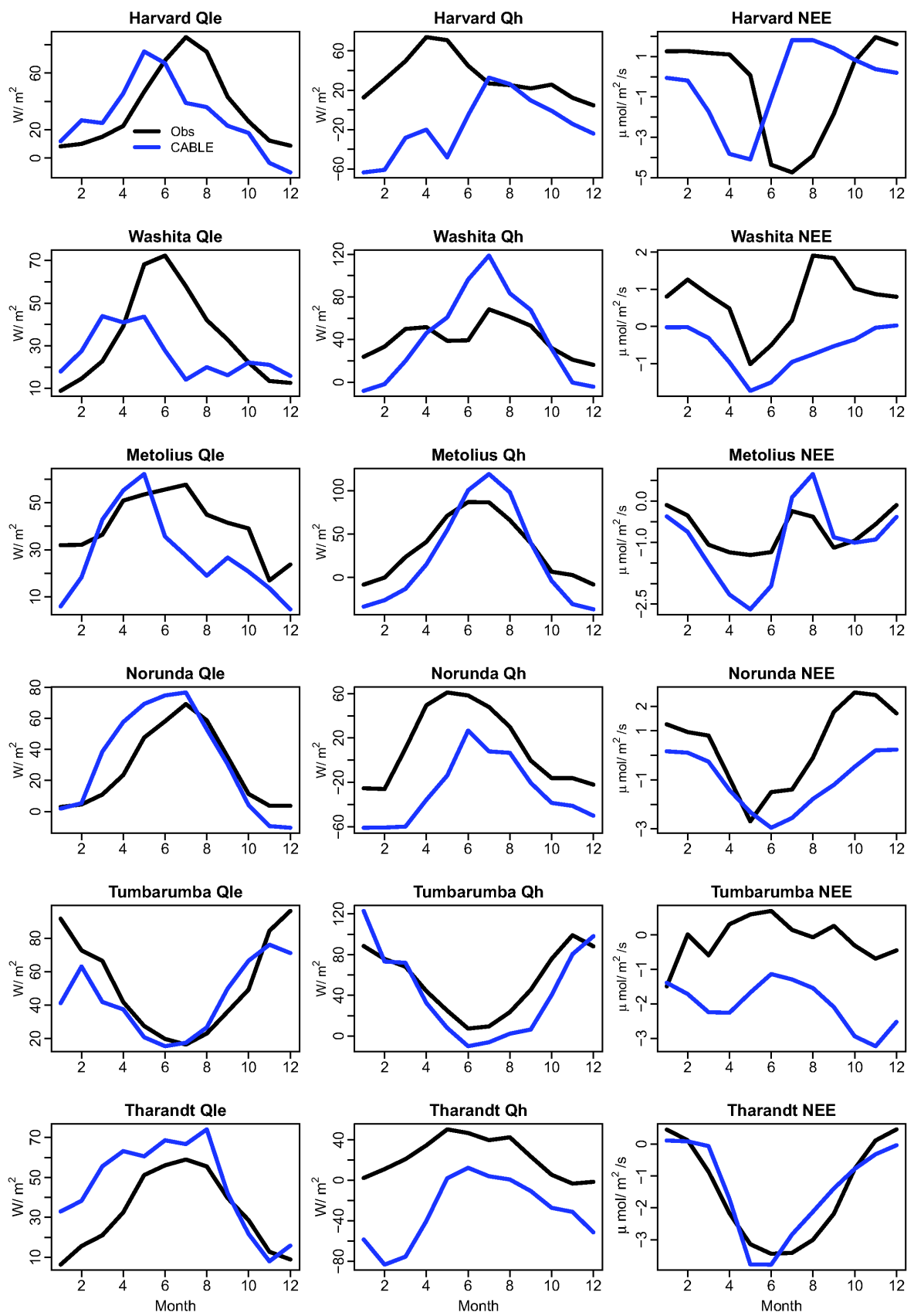

Fig. 1. Seasonal climatology observed and simulated for the six locations detailed in Table 1. The first column is the latent heat flux (W $\mathrm{m}^{-2}$ ), the second column is the sensible heat flux $\left(\mathrm{W} \mathrm{m}^{-2}\right)$, and the third column is the net ecosystem exchange of $\mathrm{CO}_{2}\left(\mu \mathrm{mol} \mathrm{m}{ }^{-2} \mathrm{~s}^{-1}\right)$.

\section{Coupled model experimental design}

\subsection{Experimental details}

Two atmosphere-sea ice-land surface model simulations were conducted, both integrated for $50 \mathrm{yr}$, with the only difference being the land surface model. We principally focus on results averaged over the last $30 \mathrm{yr}$. Both simulations were initialised from the final state of a previous experiment that was integrated for $500 \mathrm{yr}$. The model was then integrated from this initial state for $50 \mathrm{yr}$ under pre-industrial boundary conditions. The atmospheric carbon dioxide concentration was set to $280 \mathrm{ppm}$, the solar constant to $1365 \mathrm{~W} \mathrm{~m}^{-2}$, and modern values were used for the Earth's orbital parameters. The bottom boundary condition was derived from the NOAA Optimum Interpolation v2 sea surface temperature analysis (Reynolds et al., 2002), with climatological sea 
Table 1. The six flux tower sites, vegetation type, location, period of record and reference to the data sets.

\begin{tabular}{llcrcl}
\hline Site name & Vegetation type & Lat & Long & Years & Reference \\
\hline Harvard Forest & Deciduous forest & $42^{\circ} 32^{\prime} \mathrm{N}$ & $72^{\circ} 10^{\prime} \mathrm{W}$ & $1992-1999$ & Barford et al. (2001) \\
Little Washita & Grass & $34^{\circ} 58^{\prime} \mathrm{N}$ & $97^{\circ} 59^{\prime} \mathrm{W}$ & $1997-1998$ & Meyers and Hollinger (2004) \\
Metolius & Coniferous forest & $44^{\circ} 30^{\prime} \mathrm{N}$ & $121^{\circ} 37^{\prime} \mathrm{W}$ & $1997-2002$ & Law et al. (1999) \\
Norunda & Coniferous forest & $60^{\circ} 05^{\prime} \mathrm{N}$ & $17^{\circ} 28^{\prime} \mathrm{E}$ & $1996-1998$ & Lundin et al. (1999) \\
Tumbarumba & Eucalyptus forest & $35^{\circ} 39^{\prime} \mathrm{S}$ & $148^{\circ} 09^{\prime} \mathrm{E}$ & $2002-2003$ & Leuning et al. (2005) \\
Tharandt & Conifer & $50^{\circ} 58^{\prime} \mathrm{N}$ & $13^{\circ} 38^{\prime} \mathrm{E}$ & $1996-2000$ & Bernhofer et al. (2003) \\
\hline
\end{tabular}

Table 2. Basic data for each flux tower site for the latent heat flux, sensible heat flux and net ecosystem exchange. These figures are derived from 30-min observed and modelled data.

\begin{tabular}{|c|c|c|c|c|c|c|c|c|c|}
\hline & \multicolumn{3}{|c|}{$\begin{array}{l}\text { Latent heat flux } \\
\qquad\left(\mathrm{W} \mathrm{m}^{-2}\right)\end{array}$} & \multicolumn{3}{|c|}{$\begin{array}{l}\text { Sensible heat flux } \\
\qquad\left(\mathrm{W} \mathrm{m}^{-2}\right)\end{array}$} & \multicolumn{3}{|c|}{$\begin{array}{l}\text { Net Ecosystem Exchange } \\
\left(\mu \mathrm{mol} \mathrm{m}{ }^{-2} \mathrm{~s}^{-1}\right)\end{array}$} \\
\hline & RMSE & $\begin{array}{l}\text { Obs } \\
\text { mean }\end{array}$ & $\begin{array}{c}\text { Model } \\
\text { mean }\end{array}$ & RMSE & $\begin{array}{l}\text { Obs } \\
\text { mean }\end{array}$ & $\begin{array}{r}\text { Model } \\
\text { mean }\end{array}$ & RMSE & $\begin{array}{r}\text { Obs } \\
\text { mean }\end{array}$ & $\begin{array}{r}\text { Model } \\
\text { mean }\end{array}$ \\
\hline Harvard Forest & 56.5 & 35.4 & 29.4 & 107.7 & 33.3 & -16.2 & 6.6 & -0.48 & -0.37 \\
\hline Little Washita & 44.4 & 34.0 & 25.9 & 76.4 & 40.8 & 42.8 & 3.4 & 0.70 & -0.60 \\
\hline Metolius & 60.8 & 40.4 & 27.7 & 66.4 & 34.2 & 24.0 & 2.8 & -0.72 & -1.00 \\
\hline Norunda & 48.1 & 27.6 & 32.9 & 75.5 & 12.8 & -28.1 & 7.4 & 0.40 & -1.03 \\
\hline Tumbarumba & 62.9 & 52.0 & 43.7 & 62.0 & 54.1 & 43.3 & 5.0 & -0.14 & 2.00 \\
\hline Tharandt & 65.2 & 32.4 & 45.7 & 94.9 & 22.6 & -29.6 & 3.9 & -1.50 & -1.39 \\
\hline
\end{tabular}

surface temperatures being calculated for the period 19822001. Soil temperatures and moisture were initialised identically; this was possible because both land surface schemes use the same configuration for soil layers. The initial carbon stores used biome-specific initialisation based on Polglase and Wang (1992).

The pre-industrial climate was chosen here as the basis for evaluation in order to study the equilibrium state of the climate system, particularly with regard to terrestrial carbon storage. Discrepancies between the simulated climate and present-day observations may arise from this choice of experimental design, although biases between the simulated preindustrial climate and 20th century observations have been shown to be very modest (Phipps et al., 2011). Present-day sea surface temperatures were used as the bottom boundary condition in the absence of high-quality reconstructions of pre-industrial ocean temperatures, although warming of the sea surface between pre-industrial times and the late 20th century amounts to only $\sim 0.5 \mathrm{~K}$ (Folland et al., 2001).

\subsection{Evaluation data sets}

For the near-surface $(2 \mathrm{~m})$ air temperature and precipitation we use a variety of observations. We use Willmott and Matsuura (2001) for temperature and precipitation (1950-1999), Legates and Willmott (1990) for temperature and precipitation (1920-1980), New et al. (2000) for temperature (1961-1990) and the NCEP-2 reanalysis (Kalnay et al., 1996) over the 1979-1998 period. We also use Xie and Arkin (1997) for 1979-1998 and the Global Precipitation Climatology Product (GPCP; Huffman et al., 1997) for 1979-2002. We select one of these climatologies for global comparisons and use the range in these estimates where possible in zonal figures. In terms of terrestrial quantities, we evaluate CABLE using several estimates for net primary productivity: a MODIS product (Zhao et al., 2005), monthly net primary productivity from the Carnegie-AmesStanford Approach (CASA) model (Potter et al., 1993; Randerson et al., 1997) and a multi-model mean net primary productivity from Cramer et al. (1999). We use the direct observations for the global maps (Zhao et al., 2005) but include the model-derived products in the zonal figures where possible. We evaluate the simulated net surface radiation product using ISCCP FD from 1983-2000 (Zhang et al., 2004).

Finally, where possible, results are compared to the range of models used in the 3rd Assessment Report (TAR) of the IPCC (McAvaney et al., 2001). We note this is not entirely reasonable as the TAR models used a coupled modelling system including a dynamic ocean model. However, many also used flux adjustment to improve performance relative to observations. Comparing our results with those from the TAR at least provides a sense of the competitiveness of Mk3L. 

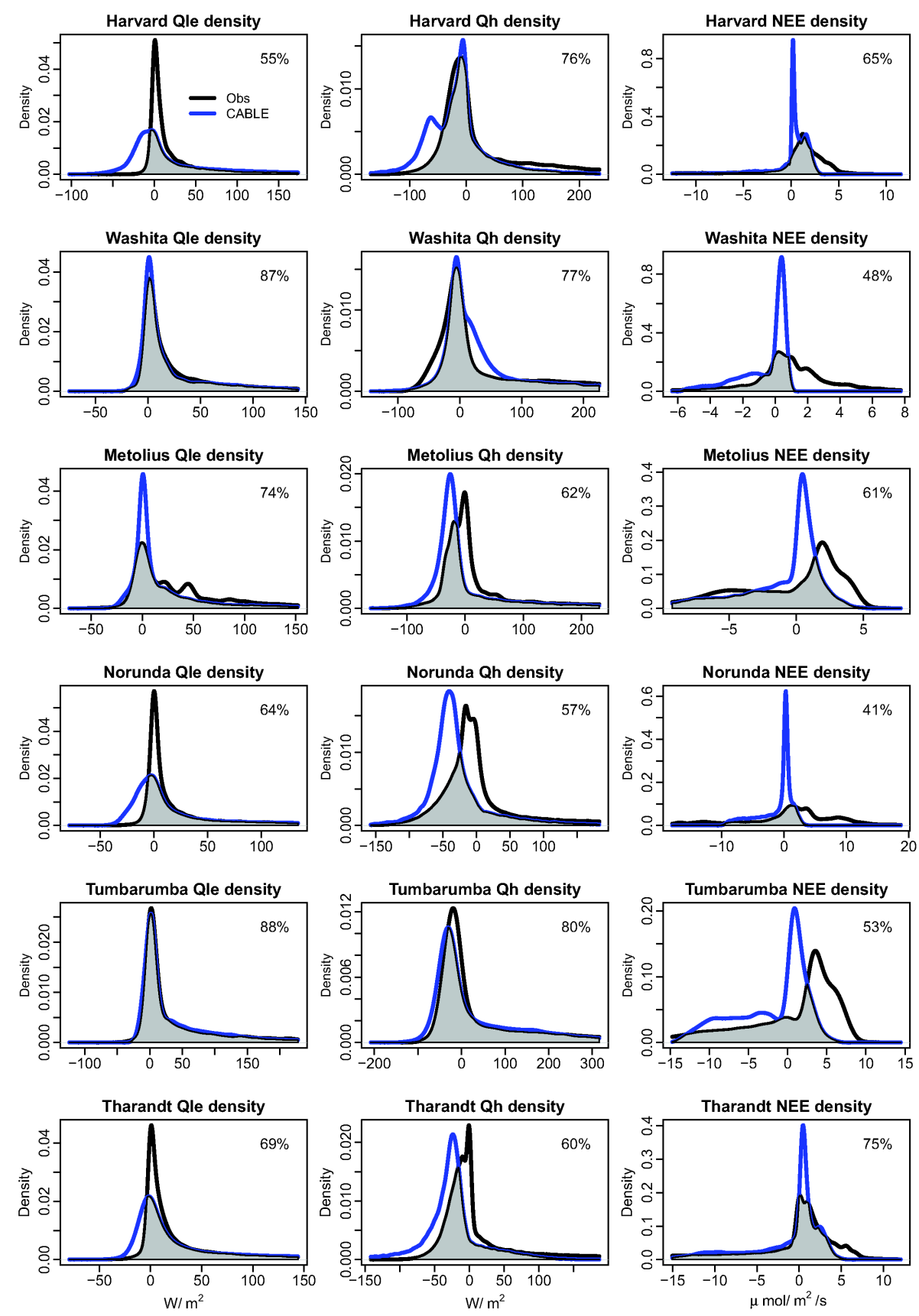

Fig. 2. Probability density functions, based on daily data, for the six locations detailed in Table 1 . The first column is the latent heat flux $\left(\mathrm{W} \mathrm{m}^{-2}\right)$, the second column is the sensible heat flux $\left(\mathrm{W} \mathrm{m}^{-2}\right)$, and the third column is the net ecosystem exchange $\left(\mu \mathrm{mol} \mathrm{m}{ }^{-2} \mathrm{~s}^{-1}\right)$. The grey shaded region on each panel shows the region of overlap and this is quantified by the numeric value shown.

\section{Results}

We present December-January-February (DJF) and JuneJuly-August (JJA) global maps for a range of quantities compared with an available data set. We also show zonallyaveraged results compared with the range of observations where possible.

\subsection{Coupled simulation of surface forcing fields}

There are three key forcing fields that a climate model has to capture realistically if the simulation of terrestrial processes including carbon is to be reliable: precipitation, temperature and net radiation.

Figure 3 shows the near-surface $(2 \mathrm{~m})$ air temperature simulated by the two versions of the model. There are several 

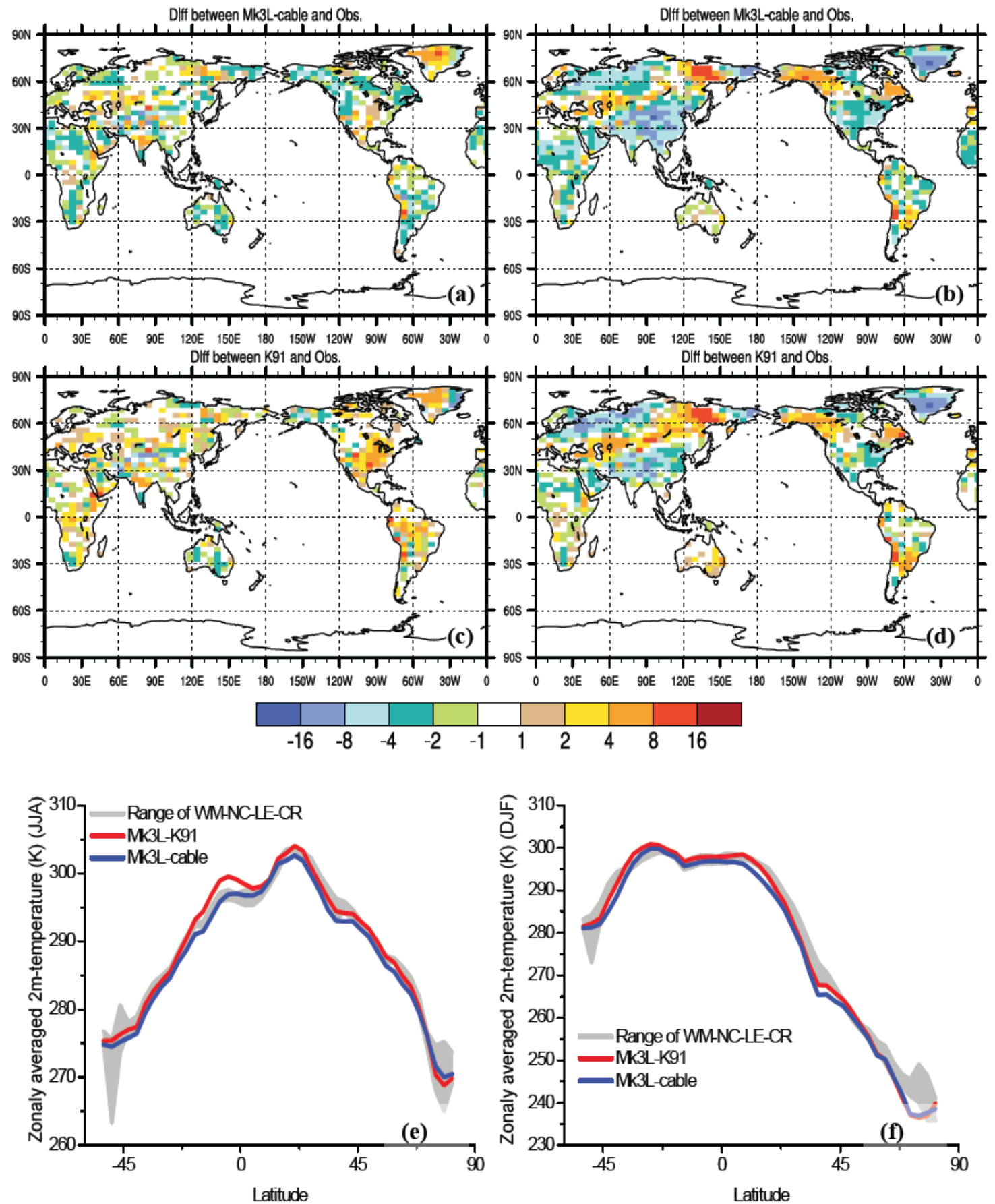

Fig. 3. The $2 \mathrm{~m}$ air temperature differences (K) relative to observations for (a) Mk3L-CABLE for JJA; (b) Mk3L-CABLE for DJF, (c) Mk3LK91 for JJA and (d) Mk3L-K91 for DJF. In each case the model is differenced from the CRU (New et al., 2000) climatology. In the lower panels the observed range is shown for WM (Willmott and Matsuura, 2001), NC (Kalnay et al., 1996), LE (Legates and Willmott, 1990) and CR (New et al., 2000). Only values over continental surfaces are shown.

observational estimates of this quantity and these are all shown (as a range) in the zonal figures. The global field shows differences between the model and observed of a similar magnitude irrespective of which land surface model is used. The global maps can be compared to Fig. 8.2 of
McAvaney et al. (2001) which shows the multi-model difference for DJF from observed for the models used in the TAR. Mk3L captures the DJF near-surface temperature on a par with the multi-model mean. There is a strong similarity in the patterns with both showing a warm bias over North America, 

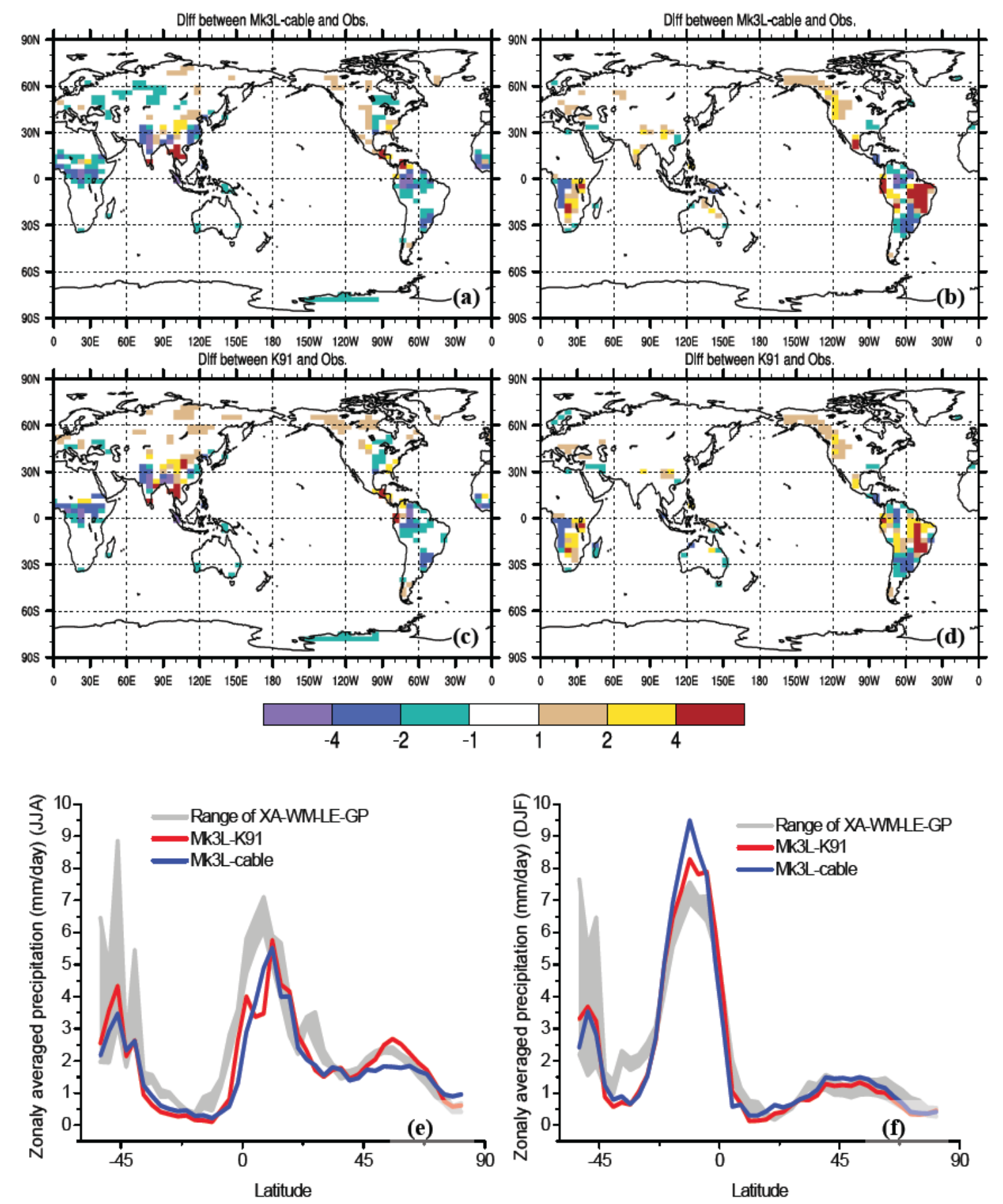

Fig. 4. As Fig. 3 but for precipitation $\left(\mathrm{mm} \mathrm{day}^{-1}\right.$ ) differenced from the CMAP precipitation rate (Xie and Arkin, 1997). In the lower panels the observed range is shown for XA (Xie and Arkin, 1997), WM (Willmott and Matsuura, 2001), LE (Legates and Willmott, 1990) and GP (Huffman et al., 1997). Only values over continental surfaces are shown.

eastern Russia and southern Australia, and a cold bias over northern Eurasia, the Himalayas, China and parts of Africa. The magnitudes of the differences are largely similar and the large-scale biases shown by Mk3L are insensitive to the land surface scheme used. The lower panels on Fig. 3 show the zonal simulation of surface temperature and the range of the observational estimates. Mk3L captures the DJF and JJA zonal gradients impressively. Comparing the DJF result with the equivalent shown in Fig. 8.2 of McAvaney et al. (2001) shows that the model is competitive with those models used in the TAR. 

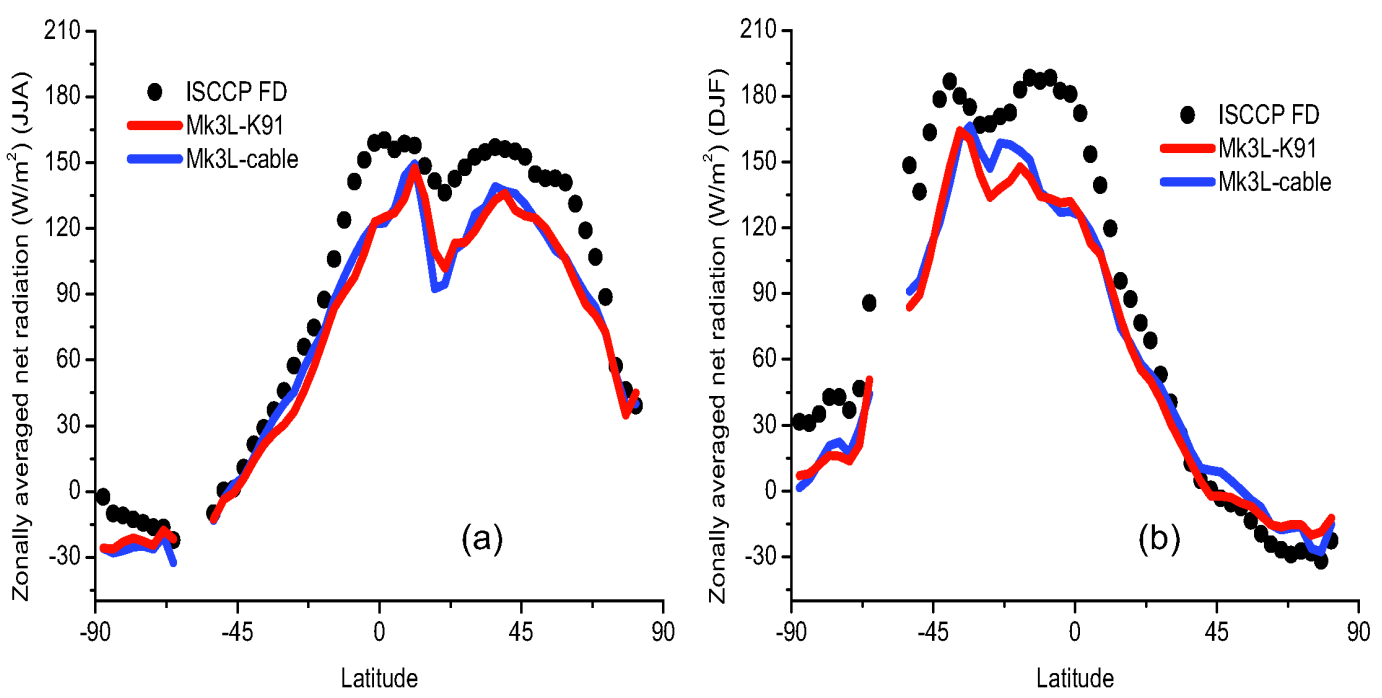

Fig. 5. Zonal net surface radiation $\left(\mathrm{W} \mathrm{m}^{-2}\right.$ ) for JJA (left) and DJF (right) for the two Mk3L simulations (observations are ISCCP FD, Zhang et al., 2004).

Figure 4 shows the precipitation field and can be compared to Fig. 8.3 (top) of McAvaney et al. (2001). As with temperature, there are similarities in the biases shown by the models used in the TAR and those shown in Fig. 4 for DJF. Both have dry biases over Amazonia although Mk3L's is more intense, both have a dry bias over the western edge of north and south America likely related to a poor representation of the Rockies and Andes, and both have a wet bias over southern Africa. Overall, Mk3L's precipitation simulation is comparable to the models used in the TAR.

The lower panels on Fig. 4 show the zonal simulation of precipitation and the range of the observational estimates. Mk3L captures the overall DJF and JJA zonal variability extremely well but there are clear anomalies in both versions of the model. The model underestimates the intensity of rainfall in JJA south of $10^{\circ} \mathrm{N}$ due to an underestimation of rainfall over the Amazon and Congo basins. The model also overestimates the intensity of DJF rainfall in the region $0-10^{\circ} \mathrm{S}$. However, tropical rainfall is a particularly difficult quantity to capture in models and the range shown in Fig. 8.3 of McAvaney et al. (2001) shows very considerable variations. Mk3L is particularly competitive, relative to most models used in the TAR, in the Northern Hemisphere. The simulated bias in the region $30-40^{\circ} \mathrm{S}$ is an area many other models have difficulties with and $\mathrm{Mk} 3 \mathrm{~L}$ is again competitive. However, the peak rainfall from Mk3L-CABLE is about $1 \mathrm{~mm} \mathrm{day}^{-1}$ higher than other models in the region $0-10^{\circ} \mathrm{S}$, and is about $1.5 \mathrm{~mm} \mathrm{day}^{-1}$ higher than the observations. This is due to excess precipitation over the Amazon Basin, as discussed in Sect. 5.2.

Figure 5 shows the difference between the observed surface net radiation and the modelled variable. The observed detailed patterns of net radiation are probably not reliable and are not shown, but the zonal estimates are likely reasonable. Mk3L underestimates net surface radiation over much of the Northern Hemisphere in JJA (Fig. 5a) by up to $30 \mathrm{~W} \mathrm{~m}^{-2}$. The model also underestimates net radiation in DJF (Fig. 5b), with the largest biases in the tropics. In other regions in DJF, Mk3L captures the zonal distribution of net radiation reasonably well. There is clearly a need to further improve the albedo parameterisation in $\mathrm{Mk} 3 \mathrm{~L}$ to enable net radiation to be captured throughout the year with higher skill.

\subsection{Coupled simulation of surface fields}

Three key fields drive terrestrial processes: net radiation, temperature and rainfall. The energy is partitioned into sensible and latent heat and used for photosynthesis assuming water is available (see Pitman, 2003). This section explores these fluxes, starting with the forcing terms and then the turbulent energy fluxes and carbon. The section focuses on the impact of the choice of land surface model on these quantities.

Coupling CABLE to Mk3L has a large impact on the net radiation in some regions (Fig. 6a and b). In JJA, CABLE receives at least $20 \mathrm{~W} \mathrm{~m}^{-2}$ more net radiation than $\mathrm{K} 91$ over equatorial Africa and the temperate regions of Asia, while it receives at least $20 \mathrm{~W} \mathrm{~m}^{-2}$ less net radiation over northern Africa. In DJF, CABLE receives at least $20 \mathrm{~W} \mathrm{~m}^{-2}$ more net radiation over China, South Africa and Australia. This is largely driven by changes in incoming solar radiation, coupled with changes in the surface albedo (Fig. 7e and f). The large differences in albedo over the northern high latitudes in DJF, which exceed $30 \%$ locally, are coincident with very low levels of incoming solar radiation. In comparison, the differences over Eurasia in JJA of 5-10 \% have a large impact 

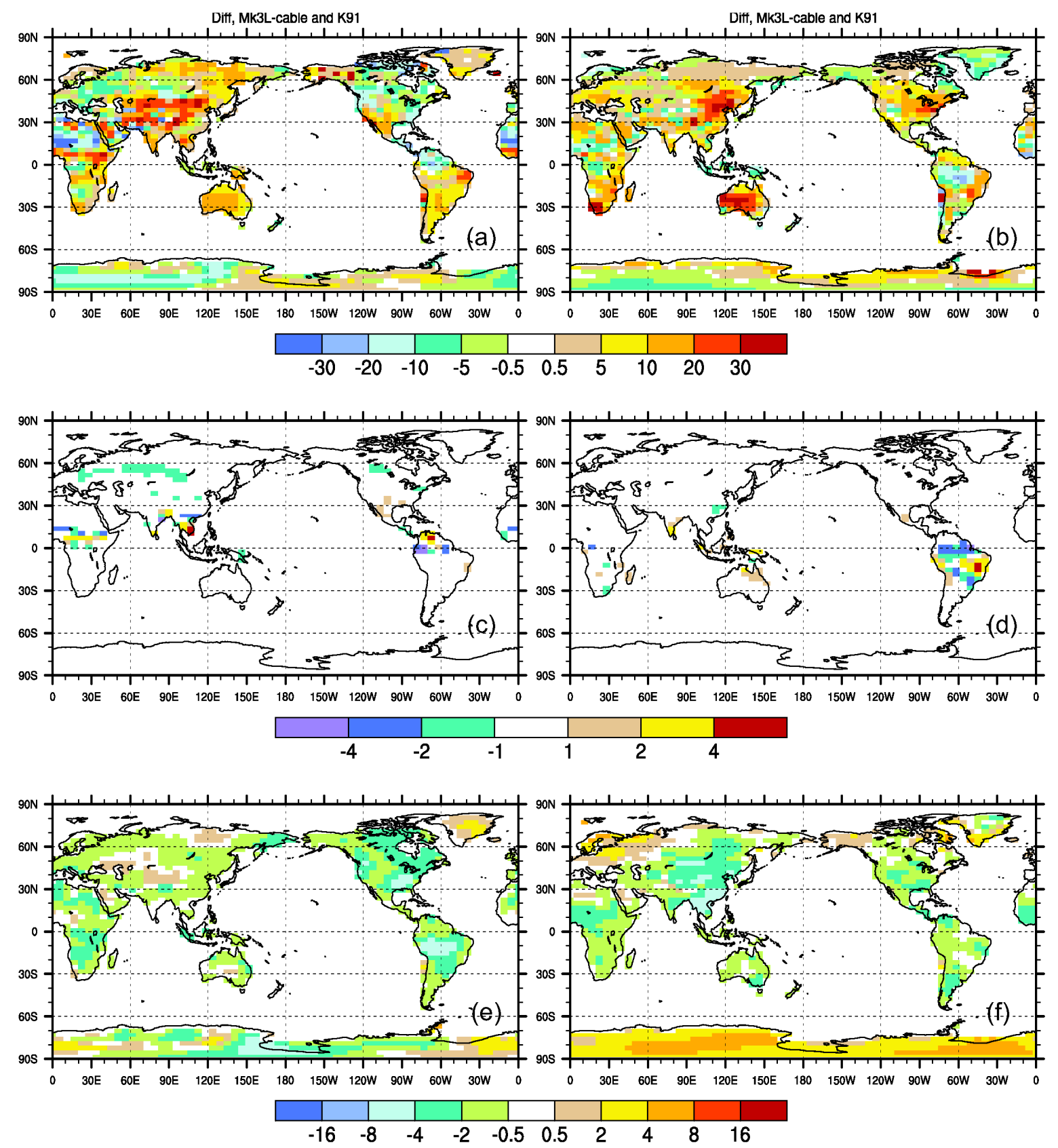

Fig. 6. Difference between Mk3L-CABLE and Mk3L-K91 for (a) net surface radiation for JJA (W m ${ }^{-2}$ ); (b) net surface radiation for DJF $\left(\mathrm{W} \mathrm{m}^{-2}\right)$; (c) precipitation for JJA $\left(\mathrm{mm} \mathrm{day}^{-1}\right)$; (d) precipitation for DJF (mm day $\left.{ }^{-1}\right)$; (e) $2 \mathrm{~m}$ air temperature for JJA (K) and (f) $2 \mathrm{~m}$ air temperature for DJF (K). Only values over continental surfaces are shown.

on net surface radiation (Fig. 6a). These changes do not drive a significant change in precipitation (Fig. $6 \mathrm{c}$ and d) except over Amazonia where in DJF CABLE receives more rainfall immediately south of the equator and less rain on the equator and at $20^{\circ} \mathrm{S}$. CABLE is cooler in JJA and DJF over most continental surfaces (Fig. 6e and f) by mainly $0.5-2{ }^{\circ} \mathrm{C}$ but locally $2-4{ }^{\circ} \mathrm{C}$ and over southern China (DJF) and Amazonia (JJA) by more than $4{ }^{\circ} \mathrm{C}$.
These changes in the forcing terms would be expected to affect the terrestrial sensible and latent heat exchange. Figure $7 \mathrm{a}$ shows a large-scale increase $\left(30-50 \mathrm{~W} \mathrm{~m}^{-2}\right)$ in sensible heat fluxes over Eurasia in JJA caused in part by the increase in net radiation (Fig. 6a), and in part by a change in the latent heat flux. However, there are also increases in sensible heat fluxes over North America despite the reduction in net radiation. This is caused more by a change in the surface moisture availability and a reduction in the latent heat flux 

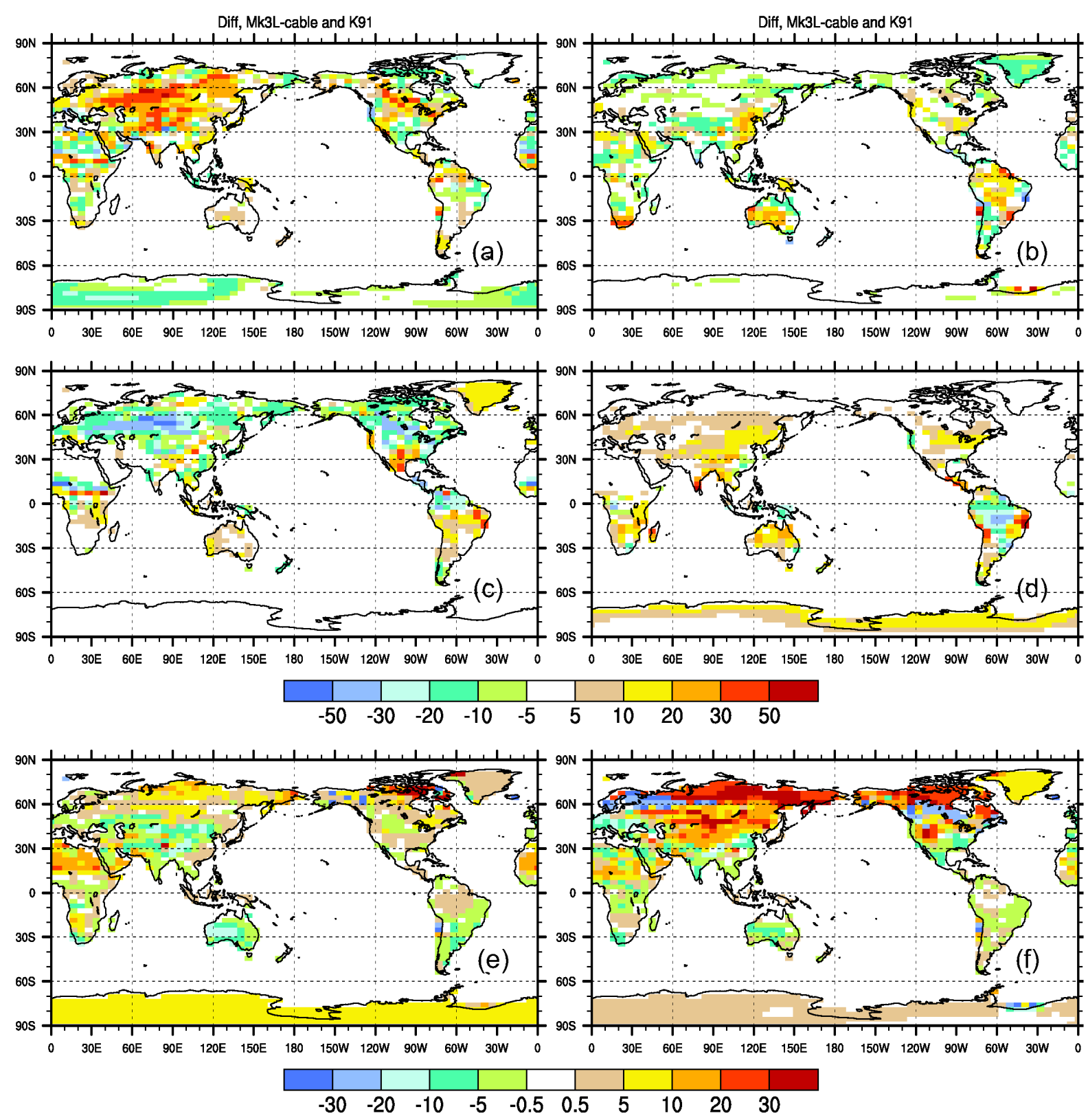

Fig. 7. Difference between Mk3L-CABLE and Mk3L-K91 for (a) sensible heat flux for JJA ( $\mathrm{W} \mathrm{m}^{-2}$ ); (b) sensible heat flux for DJF $\left(\mathrm{W} \mathrm{m}^{-2}\right)$; (c) latent heat flux for JJA $\left(\mathrm{W} \mathrm{m}^{-2}\right)$; (d) latent heat flux for DJF (W m $\left.{ }^{-2}\right)$; (e) albedo for JJA (\%); and (f) albedo for DJF (\%). Only values over continental surfaces are shown.

(Fig. 7c) than by changes in the net radiation. Thus CABLE leads to a cooler (Fig. 6e) drier surface and the suppression of latent exchange leads to the energy balance being achieved through an increase in the sensible flux. CABLE also simulates lower latent heat fluxes and higher sensible heat fluxes over Amazonia in DJF but higher latent and lower sensible fluxes in JJA (Fig. 7c and d). In general, Fig. 7 shows a pattern of CABLE simulating higher sensible heat and lower latent heat fluxes in JJA and generally lower sensible and higher latent heat fluxes in DJF compared to K91.
The simulation by CABLE of the net primary productivity (NPP) of the continental surfaces, in comparison with observations (MODIS), is shown in Fig. 8 (note K91 does not simulate these quantities). CABLE captures the basic pattern of NPP, with high values over the tropics, southern China and tropical Africa, and low values over the deserts of North Africa and Australia. There is a strong sense that the basic low NPP values at high latitudes and the transition to higher values in the temperate regions, increasing further to the tropics, is captured. Figure $8 \mathrm{c}$ shows the difference 

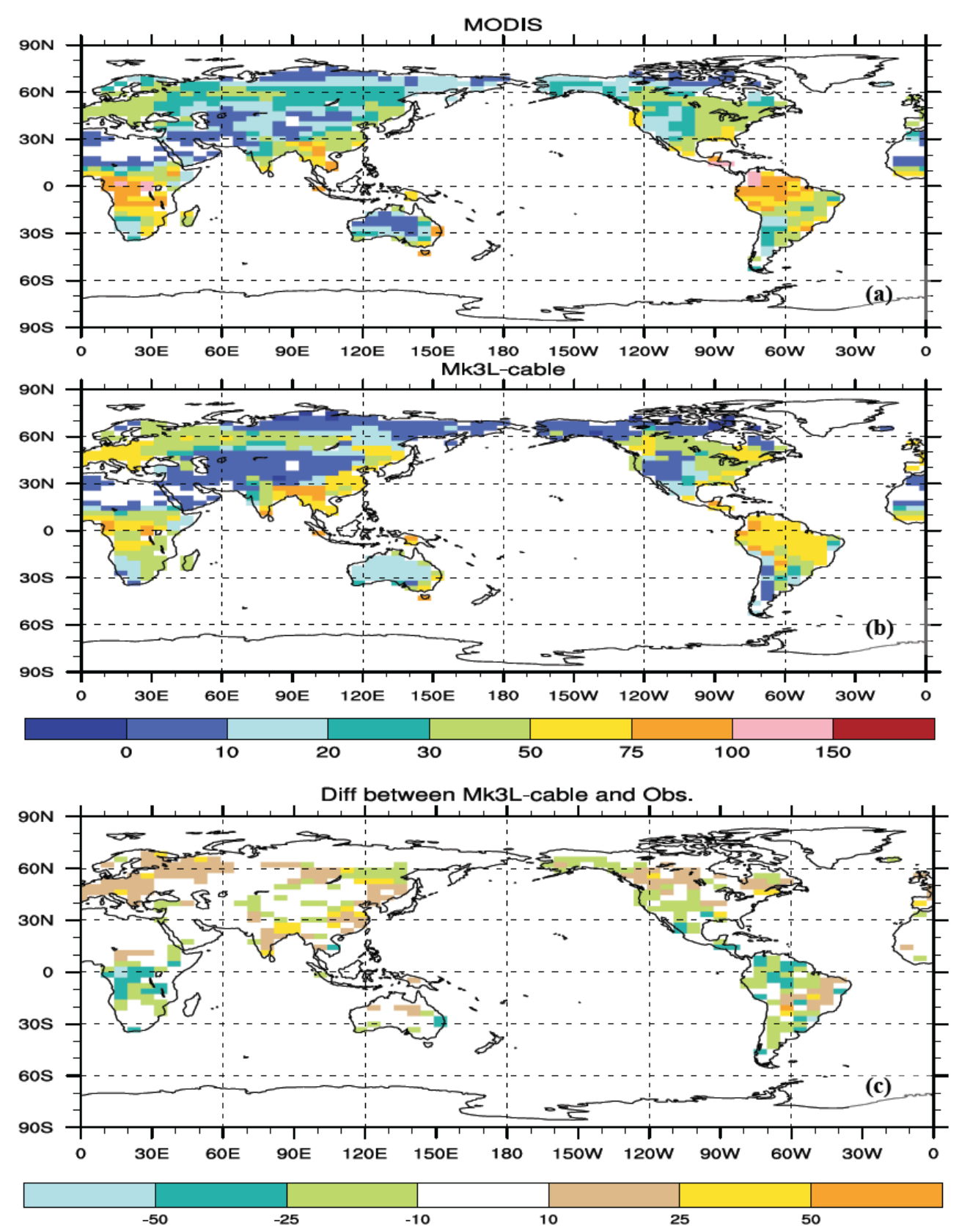

Fig. 8. Annual mean net primary productivity $\left(\mathrm{g} \mathrm{C} \mathrm{m}^{-2} \mathrm{month}^{-1}\right.$ ) from (a) MODIS MOD 17-vegetation production (Zhao et al., 2005); (b) Mk3L-CABLE and (c) Mk3L-CABLE minus observations.

between CABLE and observations. Most regions are simulated to within $\pm 25 \mathrm{~g} \mathrm{C} \mathrm{m}^{-2}$ month $^{-1}$. In some regions of high observed NPP this is satisfactory but errors of order $25 \mathrm{~g} \mathrm{C} \mathrm{m}^{-2}$ month $^{-1}$ are large relative to the observed NPP in temperate regions. Figure 9 shows zonal plots and provides evidence of both overall strong performance by CABLE and areas of model limitations. Figure 9a shows the seasonal variation in the global mean NPP. While CABLE overestimates NPP in the first and last parts of the year, the ability to capture this seasonality is reassuring. The zonal mean
(Fig. 9b) shows CABLE's simulation of annual NPP is within the observational uncertainty south of $35^{\circ} \mathrm{S}$ and over most of the Northern Hemisphere. CABLE clearly underestimates NPP in the tropics (see Fig. 9b), a systematic bias affecting tropical Africa, Amazonia and (where resolved) south-east Asia. This bias is serious between $10^{\circ} \mathrm{S}$ and $10^{\circ} \mathrm{N}$ where CABLE underestimates NPP by about $25 \%$. Using an estimate of JJA and DJF NPP from the CASA model (Randerson et al., 1997), Fig. 9c and d shows the zonal performance of CABLE. In JJA CABLE captures the zonal variability well. 

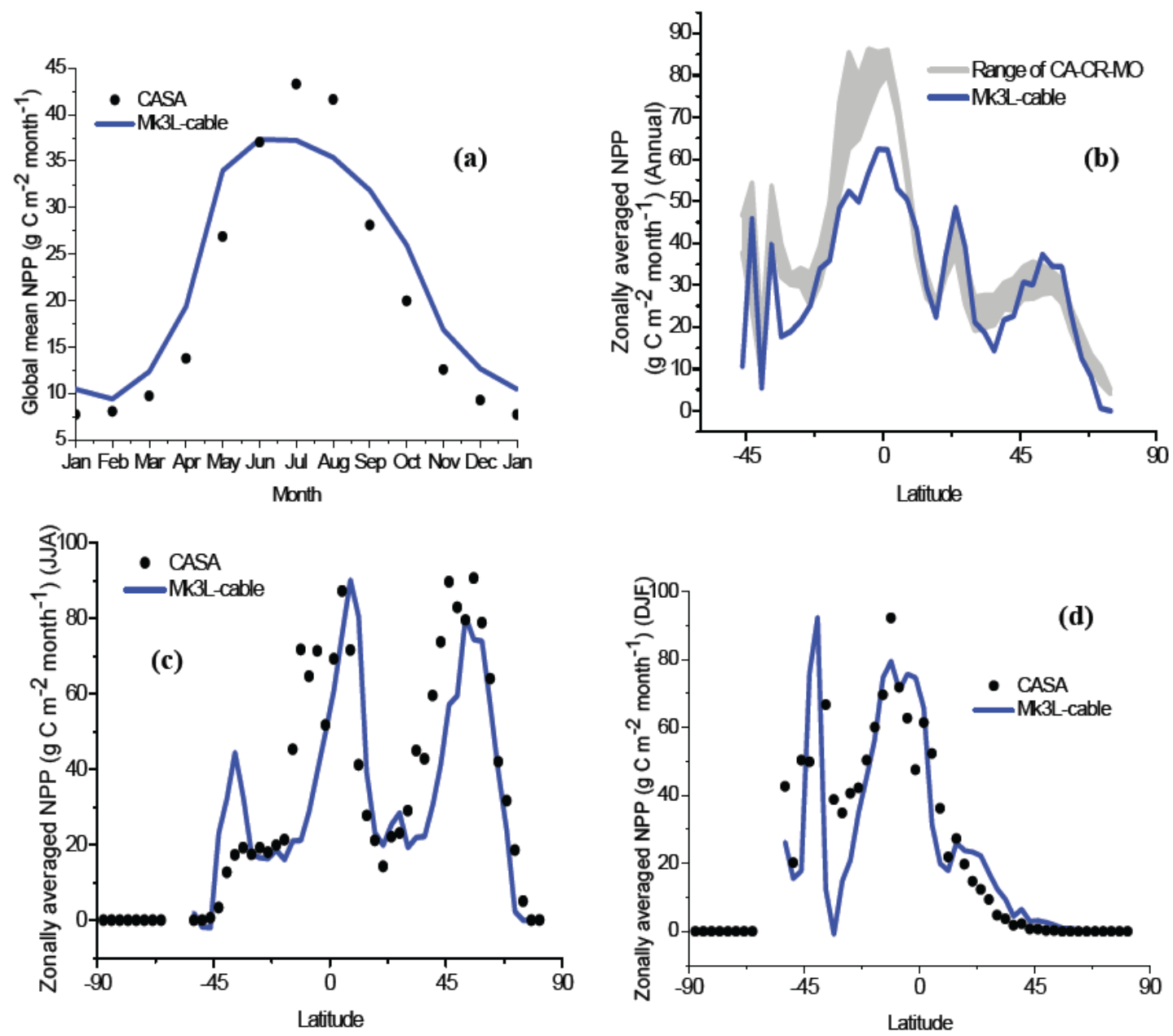

Fig. 9. Net primary productivity $\left(\mathrm{g} \mathrm{C} \mathrm{m}^{-2}\right.$ month $^{-1}$ ) for (a) global mean values compared with the estimate from CASA (Randerson et al., 1997); (b) annual net primary productivity simulated by Mk3L-CABLE compared with the range of estimates from CA (Randerson et al., 1997), CR (Cramer et al., 1999) and MO (Zhao et al., 2005); (c) zonally averaged JJA net primary productivity compared with CASA; and (d) zonally averaged DJF net primary productivity compared with CASA.

The model captures the Northern Hemisphere gradient in NPP and the summer hemisphere peak in NPP, as well as the large-scale gradient in the Southern Hemisphere. There are of course limitations and CABLE underestimates NPP around $10^{\circ} \mathrm{S}$ and overestimates NPP in $30-40^{\circ} \mathrm{S}$. The gradient of increasing NPP in the Northern Hemisphere summer is also underestimated between $40-50^{\circ} \mathrm{N}$ but the errors are relatively small (of order $10 \%$ ). In the DJF season the simulated Northern Hemisphere gradient is in excellent agreement with CASA, as is most of the variation through the tropics. CABLE underestimates NPP in the region $20-30^{\circ} \mathrm{S}$ by at least $50 \%$ however. Overall, CABLE's performance in simulating NPP is one of the strengths of Mk3L. While Fig. 8 showed that there were significant regional weaknesses, the overall pattern of NPP seasonally and latitudinally provides considerable confidence in the utility of this model.
To summarise the performance of CABLE in comparison to K91 in Mk3L, JJA and DJF global land means, biases and RMSEs are shown in Table 3 . These are primarily provided to benchmark this version of Mk3L and to act as a reference for future versions. As discussed above, there are both positives and negatives to replacing K91 with CABLE at the global land scale. In part, these are slightly misleading because Mk3L coupled with K91 has undergone extensive calibration over several years while CABLE is a much newer addition. Overall, the air temperature and precipitation simulations are largely comparable. The CABLE simulation of net surface radiation is slightly improved. While the overall impact of adding CABLE does not strongly improve Mk3L, the capacity of CABLE to simulate net primary productivity rather well (Table 1) provides a major rationale for this specific model development. 
Table 3. The June-July-August (JJA), December-January-February (DJF) and annual means, biases and root-mean-square errors (RMSE) for selected variables over the global land surface, excluding Antarctica. The observational data is the same as that shown in Figs. 3, 4, 5 and 9, and is remapped to the Mk3L grid using bilinear interpolation prior to the bias and RMSE calculations. Net primary productivity is not calculated by Mk3L-K91.

\begin{tabular}{|c|c|c|c|c|c|c|c|}
\hline & \multirow[t]{2}{*}{ Observations } & \multicolumn{3}{|c|}{ Mk3L-CABLE } & \multicolumn{3}{|c|}{ Mk3L-K91 } \\
\hline & & Mean & Bias & RMSE & Mean & Bias & RMSE \\
\hline & \multicolumn{7}{|c|}{$2 \mathrm{~m}$ air temperature $(\mathrm{K})$} \\
\hline JJA & 292.7 & 291.9 & -0.8 & 2.7 & 293.2 & +0.5 & 2.7 \\
\hline DJF & 278.3 & 276.5 & -1.8 & 4.3 & 277.8 & -0.6 & 3.9 \\
\hline \multirow[t]{2}{*}{ Annual } & 285.9 & 284.5 & -1.4 & 3.0 & 285.9 & +0.1 & 2.6 \\
\hline & \multicolumn{7}{|c|}{ Precipitation $\left(\mathrm{mm} \mathrm{day}^{-1}\right)$} \\
\hline JJA & 2.25 & 1.85 & -0.40 & 1.78 & 1.98 & -0.27 & 1.71 \\
\hline DJF & 1.94 & 2.10 & +0.16 & 1.62 & 1.98 & +0.03 & 1.39 \\
\hline \multirow[t]{2}{*}{ Annual } & 2.03 & 1.98 & -0.05 & 1.07 & 1.98 & -0.05 & 1.03 \\
\hline & \multicolumn{7}{|c|}{ Net surface radiation $\left(\mathrm{W} \mathrm{m}^{-2}\right)$} \\
\hline JJA & 129.9 & 105.5 & -24.3 & 31.7 & 103.3 & -26.5 & 33.2 \\
\hline DJF & 71.9 & 60.7 & -11.1 & 29.1 & 56.4 & -15.4 & 29.2 \\
\hline \multirow[t]{2}{*}{ Annual } & 98.8 & 83.0 & -15.8 & 25.5 & 80.3 & -18.5 & 26.4 \\
\hline & \multicolumn{7}{|c|}{ Net primary productivity $\left(\mathrm{g} \mathrm{C} \mathrm{m}^{-2}\right.$ month $\left.^{-1}\right)$} \\
\hline JJA & 48.2 & 39.5 & -8.7 & 37.7 & - & - & - \\
\hline DJF & 22.2 & 22.5 & +0.3 & 25.1 & - & - & - \\
\hline Annual & 31.8 & 30.3 & -1.5 & 23.0 & - & - & - \\
\hline
\end{tabular}

\section{Discussion and conclusions}

This paper has evaluated the atmosphere-sea ice-land surface component of the CSIRO Mk3L climate system model version 1.0, and has shown that it performs on a par with those models used in the 3rd Assessment Report of the Intergovernmental Panel on Climate Change. These models had a spatial resolution that was similar to $\mathrm{Mk} 3 \mathrm{~L}$ and, while some state-of-the-art coupled models simulate the observed climate better than Mk3L (see Randall et al., 2007), these could not be routinely used for multi-millennial climate simulations or to conduct large ensembles. This provides the rationale for slightly simplified but computationally efficient models like Mk3L.

The coupling of Mk3L to CABLE provided the opportunity to evaluate the impact of land surface processes on the simulated climate. We showed that $\mathrm{Mk} 3 \mathrm{~L}$ can capture temperature and rainfall reasonably well over the continental surfaces, and that these large-scale simulations were not substantially affected by the choice of land surface scheme. However, coupling CABLE to Mk3L significantly altered the net radiation and therefore the partitioning of net radiation between sensible and latent heat. This in turn led to regional modifications to the near-surface air temperature field. However, it is unlikely that we could demonstrate that adding
CABLE to Mk3L led to a superior climate simulation. K91 was carefully configured to work well at large-scales given the limitations of climate models and CABLE has yet to undergo the decade of calibration and configuration to similarly optimise the performance of the scheme. However, there is no evidence that coupling CABLE degrades the climate simulation of Mk3L significantly relative to the existing biases - that is, there is no evidence that the errors in $\mathrm{Mk} 3 \mathrm{~L}$ are directly attributable to the terrestrial model. In the simulation of temperature, the remaining biases in $\mathrm{Mk} 3 \mathrm{~L}$ are different between CABLE and K91 but not generally larger with one scheme. CABLE appears to degrade the simulation of DJF tropical rainfall (Fig. 4) but only by $\sim 1 \mathrm{~mm} \mathrm{day}^{-1}$. The large regional-scale change in net radiation (Fig. 6a) is probably an improvement in CABLE (see Fig. 5a) since the modelled flux coupled to CABLE is closer to the observations around 20$40^{\circ} \mathrm{N}$ than with the original scheme. However, with only one observational data set it is important to be cautious. These large changes in net radiation cause changes in the partitioning of available energy between the sensible and latent heat fluxes (Fig. 7) and while it is tempting to suggest that CABLE is likely better because the net radiation is better, several independent observational data sets would be necessary to conclude this definitively. 
While it may be difficult to argue that adding CABLE to Mk3L significantly enhances the global climate simulation, the addition does significantly improve the utility of the climate model. Specifically, the new model can simulate the terrestrial carbon balance. Figure 8 shows regional differences between the observed and modelled estimates in NPP exceeding $\pm 10 \mathrm{~g} \mathrm{C} \mathrm{m}^{-2}$ month $^{-1}$ which is large, although Fig. 9 provided strong evidence that the model could capture the global large scale seasonality, the annual NPP and the seasonally averaged zonal variability in NPP remarkably well. This is likely a result driven to first order by a good global temperature, rainfall and net radiation simulation since the calculation of NPP is largely driven by these quantities. The biases that remain (Fig. 8) may be related to errors in the forcing, or more likely related to more regionally-specific characteristics in the vegetation that CABLE has yet to resolve.

The addition of terrestrial carbon and the evaluation of NPP suggest that the model can capture the basic processes that control NPP. Overall therefore, $\mathrm{Mk} 3 \mathrm{~L}$ is a valuable and robust tool for millennium-scale simulations. Its relatively strong climatology, its numerical efficiency and its inclusion of terrestrial carbon makes it a particularly valuable tool to explore long-time scale behavior in the climate system and we aim to report on these experiments in the future. The community plans to continue to enhance this model via the addition of ocean biogeochemistry, dynamic vegetation and nutrients and aerosols to gradually build a more complete Earth System Model capable of millennium-scale integrations.

Acknowledgements. This research was undertaken on the NCI National Facility in Canberra, Australia, which is supported by the Australian Commonwealth Government. This work was supported by ARC Linkage grant LP0774996. The first author was supported in part by the US Department of Energy (DOE), Office of Science, Biological and Environmental Research. Oak Ridge National Laboratory is managed by UT-BATTELLE for DOE under contract DE-AC05-00OR22725.

Edited by: R. Marsh

\section{References}

Abramowitz, G.: Towards a benchmark for land surface models, Geophys. Res. Lett., 32, L22702, doi:10.1029/2005GL024419, 2005.

Abramowitz, G., Leuning, R. M. C., and Pitman, A. J.: Evaluating the performance of land surface models, J. Climate, 21, 54685481, doi:10.1175/2008JCLI2378.1, 2008.

Barford, C. C., Wofsy, S. C., Goulden, M. L., Munger, J. W., Pyle, E. H., Urbanski, S. P., Hutyra, L., Saleska, S. R., Fitzjarrald, D., and Moore, K.: Factors controlling long- and short-term sequestration of atmospheric $\mathrm{CO}_{2}$ in a midlatitude forest, Science, 294, 1688-1691, doi:10.1126/science.1062962, 2001.

Bernhofer, C., Aubinet, M., Clément, R., Grelle, A., Grünwald, T., Ibrom, A., Jarvis, P., Rebmann, C., Schulze, E.-D., and Ten- hunen, J.: Spruce forests (Norway and Sitka spruce, including Douglas fir): Carbon and water fluxes, Balances, Ecological and ecophysiological determinants, in: Fluxes of Carbon, Water and Energy of European Forests, edited by: Valentini, R., SpringerVerlag, Berlin, Germany, 99-124, 2003.

Claussen, M., Mysak, L. A., Weaver, A. J., Crucifix, M., Fichefet, T., Loutre, M.-F., Weber, S. L., Alcamo, J., Alexeev, V. A., Berger, A., Calov, R., Ganopoloski, A., Goosse, H., Lohmann, G., Lunkeit, F., Mokhov, I. I., Petoukhov, V., Stone, P., and Wang, Z.: Earth system models of intermediate complexity: closing the gap in the spectrum of climate system models, Clim. Dynam., 18, 579-586, doi:10.1007/s00382-001-0200-1, 2002.

Cox, P. M., Betts, R. A., Jones, C. D., Spall, S. A., and Totterdell, I. J.: Acceleration of global warming due to carbon-cycle feedbacks in a coupled climate model, Nature, 408, 184-187, 2000.

Cramer, W., Kicklighter, D. W., Bondeau, A., Moore, B., and Chrukina, G.: Comparing global models of terrestrial net primary productivity (NPP): overview and key results, Glob. Change Biol., 5 (Supp. 1), 1-15, 1999.

Dickinson, R. E., Shaikh, M., Bryant, R., and Graumlich, L.: Interactive canopies for a climate model, J. Climate, 11, 2823-2836, 1998.

Finkele, K., Katzfey, J. J., Kowalczyk, E. A., McGregor, J. L., Zhang, L., and Raupach, M. R.: Modelling of the OASIS energy flux measurements using two canopy concepts, Bound.-Lay. Meteorol., 107, 49-79, 2003.

Fischer, E. M., Seneviratne, S. I., Luthi, D., and Schär, C. The contribution of land-atmosphere coupling to recent European summer heatwaves, Geophys. Res. Lett., 34, L06707, doi:10.1029/2006GL029068, 2007.

Folland, C. K., Karl, T. R., Christy, J. R., Clarke, R. A., Gruza, G. V., Jouzel, J., Mann, M. E., Oerlemans, J., Salinger, M. J., and Wang, S.-W.: Observed Climate Variability and Change, in: Climate Change 2001: The Scientific Basis, edited by: Houghton, J. T., Ding, Y., Griggs, D. J., Noguer, M., van der Linden, P. J., Dai, X., Maskell, K., and Johnson, C. A., chap. 2, 99-181, Cambridge University Press, 2001.

Henderson-Sellers, A., Pitman, A. J., Love, P. K., Irannejad, P., and Chen, T. H.: The Project for Intercomparison of Land Surface Parameterizaton Schemes (PILPS): Phases 2 and 3, B. Am. Meteorol. Soc., 76, 489-503, 1995.

Houghton, J. T., Filho, L. G. M., Callander, B. A., Harris, N., Kattenberg, A., and Maskell, K.: Climate Change 1995: The Science of Climate Change, Cambridge University Press, Cambridge, UK, 1996.

Huffman, G. J., Adler, R. F., Arkin, P., Chang, A., Ferraro, R., Gruber, A., Janowiak, J., McNab, A., Rudolf, B., and Schneider, U.: The Global Precipitation Climatology Project (GPCP) Combined Precipitation Dataset, B. Am. Meteorol. Soc., 78, 5-20, 1997.

Jarvis, P. G.: The interpretation of the variations in leaf water potential and stomatal conductance found in canopies in the field, Philos. T. Roy. Soc. B, 273, 593-610, 1976.

Kalnay, E., Kanamitsu, M., Kistler, R., Collins, W., Deaven, D., Gandin, L., Iredell, M., Saha, S., White, G., Woollen, J., Zhu, Y., Chelliah, M., Ebisuzaki, W., Higgins, W., Janowiak, J., Mo, K., Ropelewski, C., Wang, J., Leetmaa, A., Reynolds, R., Jenne, R., and Joseph, D.: The NCEP/NCAR 40-year reanalysis project, B. Am. Meteorol. Soc., 77, 437-470, 1996.

Kowalczyk, E. A., Garratt, J. R., and Krummel, P. B.: A Soil- 
Canopy Scheme for Use in a Numerical Model of the Atmosphere - 1D Stand-Alone Model, Technical Paper 23, CSIRO Division of Atmospheric Research, available at: http://www.cmar. csiro.au/e-print/open/kowalczyk_1991a.pdf (last access: June 2011), 1991.

Kowalczyk, E. A., Garratt, J. R., and Krummel, P. B.: Implementation of a Soil-Canopy Scheme into the CSIRO GCM Regional Aspects of the Model Response, Technical Paper 32, CSIRO Division of Atmospheric Research, available at: http: //www.cmar.csiro.au/e-print/open/kowalczyk_1994a.pdf (last access: June 2011), 1994.

Kowalczyk, E. A., Wang, Y. P., Law, R. M., Davies, H. L., McGregor, J. L., and Abramowitz, G.: The CSIRO Atmosphere Biosphere Land Exchange (CABLE) model for use in climate models and as an offline model, CSIRO Marine and Atmospheric Research Paper 013, CSIRO Marine and Atmospheric Research, available at: http://www.cmar.csiro.au/e-print/open/ kowalczykea_2006a.pdf (last access: June 2011), 2006.

Law, B. E., Ryan, M. G., and Anthoni, P. M.: Seasonal and annual respiration of a ponderosa pine ecosystem, Glob. Change Biol., 5, 169-182, 1999.

Legates, D. R. and Willmott, C. J.: Mean Seasonal and Spatial Variability in Gauge-Corrected, Global Precipitation, Int. J. Climatol., 10, 111-127, 1990.

Leuning, R., Kelliher, F. M., de Pury, D. G. G., and Schulze, E.D.: Leaf nitrogen, photosynthesis, conductance and transpiration: scaling from leaves to canopies, Plant Cell Environ., 18, 1183-1200, 1995.

Leuning, R., Cleugh, H. A., Zegelin, S. J., and Hughes, D.: Carbon and water fluxes over a temperate Eucalyptus forest and a tropical wet/dry savanna in Australia: Measurements and comparison with MODIS remote sensing estimates, Agr. Forest Meteorol., 129, 151-173, doi:10.1016/j.agrformet.2004.12.004, 2005.

Lundin, L.-C., Halldin, S., Lindroth, A., Cienciala, E., Grelle, A., Hjelm, P., Kellner, E., Lundberg, A., Mölder, M., Morén, A.S., Nord, T., Seibert, J., and Stähli, M.: Continuous long-term measurements of soil-plant-atmosphere variables at a forest site, Agr. Forest Meteorol., 98-99, 53-73, 1999.

McAvaney, B. J., Covey, C., Joussaume, S., Kattsov, V., Kitoh, A., Ogana, W., Pitman, A. J., Weaver, A., Wood, R. A., and Zhao, Z.C.: Model Evaluation, in: Climate Change 2001: The Scientific Basis, edited by: Houghton, J. T., Ding, Y., Griggs, D. J., Noger, M., van der Linden, P. J., Dai, X., Maskell, K., and Johnson, C. A., Cambridge University Press, Cambridge, UK, chap. 8, 471-523, 2001.

Meyers, T. P. and Hollinger, S. E.: An assessment of storage terms in the surface energy balance of maize and soybean, Agr. Forest Meteorol., 125, 105-115, doi:10.1016/j.agrformet.2004.03.001, 2004.

New, M. G., Hulme, M., and Jones, P. D.: Representing 20th century space-time climate variability, II: Development of 19011996 monthly terrestrial climate fields, J. Climate, 13, 22172238, 2000.

Phipps, S. J., Rotstayn, L. D., Gordon, H. B., Roberts, J. L., Hirst, A. C., and Budd, W. F.: The CSIRO Mk3L climate system model version 1.0 - Part 1: Description and evaluation, Geosci. Model Dev., 4, 483-509, doi:10.5194/gmd-4-483-2011, 2011.

Pitman, A. J.: The evolution of, and revolution in, land surface schemes designed for climate models, Int. J. Climatol., 23, 479-
510, doi:10.1002/joc.893, 2003.

Polglase, P. J. and Wang, Y. P.: Potential $\mathrm{CO}_{2}$-enhanced carbon storage by the terrestrial biosphere, Aust. J. Bot., 40, 641-656, 1992.

Potter, C. S., Randerson, J. T., Field, C. B., Matson, P. A., Vitousek, P. M., Mooney, H. A., and Klooster, S. A.: Terrestrial ecosystem production: A process model based on global satellite and surface data, Global Biogeochem. Cy., 7, 811-841, 1993.

Randall, D. A., Wood, R. A., Bony, S., Colman, R., Fichefet, T., Fyfe, J., Kattsov, V., Pitman, A., Shukla, J., Srinivasan, J., Stouffer, R. J., Sumi, A., and Taylor, K. E.: Climate Models and Their Evaluation, in: Climate Change 2007: The Physical Science Basis, edited by: Solomon, S., Qin, D., Manning, M., Chen, Z., Marquis, M., Averyt, K. B., Tignor, M., and Miller, H. L., Cambridge University Press, Cambridge, UK, chap. 8, 589-662, 2007.

Randerson, J. T., Thompson, M. V., Conway, T. J., Fung, I. Y., and Field, C. B.: The contribution of terrestrial sources and sinks to trends in the seasonal cycle of atmospheric carbon dioxide, Global Biogeochem. Cy., 11, 535-560, 1997.

Raupach, M. R.: A practical Lagrangian method for relating scalar concentrations to source distributions in vegetation canopies, Q. J. Roy. Meteor. Soc., 115, 609-632, 1989.

Raupach, M. R.: Simplified expressions for vegetation roughness length and zero-plane displacement as functions of canopy height and area index, Bound.-Lay. Meteorol., 71, 211-216, 1994.

Raupach, M. R., Finkele, K., and Zhang, L.: SCAM (Soil-CanopyAtmosphere Model): description and comparison with field data, Technical Report 132, CSIRO Centre for Environmental Mechanics, 1997.

Reynolds, R. W., Rayner, N. A., Smith, T. M., Stokes, D. C., and Wang, W.: An Improved In Situ and Satellite SST Analysis for Climate, J. Climate, 15, 1609-1625, 2002.

Sellers, P. J., Dickinson, R. E., Randall, D. A., Betts, A. K., Hall, F. G., Berry, J. A., Collatz, G. J., Denning, A. S., Mooney, H. A., Nobre, C. A., Sato, N., Field, C. B., and Henderson-Sellers, A.: Modeling the exchanges of energy, water and carbon between continents and the atmosphere, Science, 275, 502-509, 1997.

Seneviratne, S. I., Luthi, D., Litschi, M., and Schär, C.: Landatmosphere coupling and climate change in Europe, Nature, 443, 205-209, doi:10.1038/nature05095, 2006.

Seneviratne, S. I., Corti, T., Davin, E. L., Hirschi, M., Jaeger, E. B., Lehner, I., Orlowsky, B., and Teuling, A. J.: Investigating soil moisture-climate interactions in a changing climate: A review, Earth-Sci. Rev., 99, 125-161, doi:10.1016/j.earscirev.2010.02.004, 2010.

Wang, Y. P. and Barrett, D. J.: Estimating regional terrestrial carbon fluxes for the Australian continent using a multiple-constraint approach: I. parameter estimation using remotely sensed data and ecological observations of net primary production, Tellus, 55B, 270-289, 2003.

Wang, Y. P. and Leuning, R.: A two-leaf model for canopy conductance, photosynthesis and partitioning of available energy, I. model description, Agr. Forest Meteorol., 91, 89-111, 1998.

Wang, Y. P., Leuning, R., Cleugh, H. A., and Coppin, P. A.: Parameter estimation in surface exchange models using non-linear inversion: how many parameters can we estimate and which measurements are most useful?, Glob. Change Biol., 7, 495-510, 2001.

Wang, Y. P., Baldocchi, D., Leuning, R., Falge, E., and Vesala, 
T.: Estimating parameters in a land surface model by applying nonlinear inversion to eddy covariance flux measurements from eight FLUXNET sites, Glob. Change Biol., 13, 652-670, doi:10.1111/j.1365-2486.2006.01225.x, 2007.

Wang, Y. P., Kowalczyk, E., Leuning, R., Abramowitz, G., Raupach, M. R., Pak, B., van Gorsel, E., and Luhar, A.: Diagnosing errors in a land surface model (CABLE) in the time and frequency domains, J. Geophys. Res., 116, G01034, doi:10.1029/2010JG001385, 2011.

Willmott, C. J. and Matsuura, K.: Terrestrial Air Temperature and Precipitation: Monthly and Annual Time Series (1950-1999) Version 1.02, http://climate.geog.udel.edu/ climate/html_pages/ README.ghcn_ts2.html (last access: June 2011), 2001.
Xie, P. and Arkin, P. A.: Global precipitation: a 17-year monthly analysis based on gauge observations, satellite estimates, and numerical model outputs, B. Am. Meteorol. Soc., 78, 2539-2558, 1997.

Zhang, Y. C., Rossow, W. B., Lacis, A. A., Oinas, V., and Mishchenko, M. I.: Calculation of radiative fluxes from the surface to top of atmosphere based on ISCCP and other global data sets: Refinements of the radiative transfer model and the input data, J. Geophys. Res., 109, D19105, doi:10.1029/2003JD004457, 2004.

Zhao, M. S., Heinsch, F. A., Nemani, R. R., and Running, S. W.: Improvements of the MODIS terrestrial gross and net primary production global data set, Remote Sens. Environ., 95, 164-176, doi:10.1016/j.rse.2004.12.011, 2005. 